\title{
Anaerobic Capacity is Associated with Metabolic Contribution and Mechanical Output Measured During the Wingate Test
}

\author{
by \\ Rodrigo Araujo Bonetti de Poli1,2, Willian Eiji Miyagi1,2, \\ Alessandro Moura Zagatto ${ }^{1,2}$
}

\begin{abstract}
The study aimed to investigate the relationship between anaerobic capacity, mechanical and anaerobic contribution during the 30-s Wingate Anaerobic Test (30sWAnT). After familiarization, fifteen, male recreational mountain biking practitioners underwent the following sequence of tests: 1) a graded exercise test to determine maximal oxygen uptake and associated intensity $\left(i \mathrm{VO}_{2 \max }\right) ; 2$ and 3) supramaximal exhaustive effort at $115 \%$ of $i \mathrm{VO}_{2 \max }$ and 30sWAnT, performed randomly. The glycolytic and phosphagen pathways measured during the supramaximal effort were significantly correlated with peak power $(r=0.85 ; p<0.01$ and $r=0.57 ; p=0.02$, respectively), mean power $(r=$ $0.78 ; p<0.01$ and $r=0.69 ; p<0.01$, respectively), and total work $(r=0.78 ; p<0.01$ and $r=0.69 ; p<0.02$, respectively) measured during the 30sWAnT. A significant correlation was also found between anaerobic capacity and peak power $(r$ $=0.88 ; p<0.01)$, mean power $(r=0.89 ; p<0.01)$, and total work $(r=0.89 ; p<0.01)$. Additionally, anaerobic capacity estimated during the supramaximal effort and the anaerobic contribution measured during the 30sWAnT were not different $(p=0.44)$ and presented significant good reliability and association (ICC $=0.84 ; p=0.001$ ) and good agreement, evidenced by the mean of differences and 95\% limits of agreement near to zero (mean bias $=0.11$ ). The results suggest that glycolytic and phosphagen capacity were associated with mechanical performance in the 30sWAnT. In addition, anaerobic contribution during the 30sWAnT seems to be valid for estimating anaerobic capacity in recreational mountain bike cyclists, as well as to estimate the glycolytic and phosphagen contributions.
\end{abstract}

Key words: glycolytic pathway, phosphagen pathway, anaerobic performance, exercise metabolism, cycling.

\section{Introduction}

During high intensity short duration efforts (30 to $180 \mathrm{~s}$ ), the maximum amount of adenosine triphosphate resynthesized (ATP) by non-oxidative metabolic pathways is responsible for a substantial energetic contribution ( $\sim 70$ to 35\%, respectively) (Medbø and Tabata, 1993), playing a fundamental role in sprint running (100 to $400 \mathrm{~m}$ ) and cycling mechanical performance (500 to $1500 \mathrm{~m}$ ) (Foster et al., 2003, 2004; Spencer and Gastin, 2001), and during the end spurt of distance cycling trials $(3000 \mathrm{~m})$ (Foster et al., 2003). Considering the importance of the nonoxidative pathways for high intensity efforts, several studies have proposed methods to estimate maximum non-oxidative energy release during different high intensity efforts (i.e., anaerobic capacity) through metabolic evaluations (Medbø et al., 1988; Miyagi et al., 2017; Zagatto et al., 2018), using techniques such as muscle biopsy (Medbø et al., 1988) or through the relationship between metabolic values and mechanical power output (Bertuzzi et al., 2015; Scott et al., 1991; Zagatto et al., 2017).

Among these methods, a recent possibility proposes estimation of anaerobic capacity using classic findings from Margaria et al. (1933) and Di Prampero and Ferretti (1999) about energetic

1 - Laboratory of Physiology and Sport Performance (LAFIDE), São Paulo State University (UNESP). Bauru, SP, Brazil.

2 - Post-Graduate Program in Movement Sciences, São Paulo State University (UNESP), School of Science. Bauru, SP, Brazil. 
estimation, considering the curve decay analysis of excess post-exercise oxygen uptake to estimate the oxygen equivalent from the phosphagen pathway (EPCr) and net blood lactate concentration corresponding to the oxygen equivalent from the glycolytic pathway (E[La-]), and thus assuming anaerobic capacity as the sum of E[La-] and EPCr (AC[Epcr + La-]) during a single exhaustive supramaximal continuous effort (Bertuzzi et al., 2010). This method was validated (compared with the most accepted method; maximal accumulated oxygen deficit) to estimate anaerobic capacity at intensities between 100 and $150 \%$ of intensity corresponding to maximal oxygen uptake, suggesting that anaerobic capacity can be estimated even in a short duration effort (i.e., $\sim 53$ s), although the $115 \%$ supramaximal intensity presented higher correlations and agreement values (Zagatto et al., 2016).

In addition, AC[Epcr + La-] is a valid method to estimate anaerobic capacity, and a comparison with other anaerobic procedures could strengthen the protocol, due to the similar energy resynthesis through non-oxidative metabolism in these efforts, such as the $30 \mathrm{~s}$ Wingate Anaerobic Test (30sWAnT) (Scott et al., 1991). The 30sWAnT is a widely used test to estimate mechanical work associated with nonoxidative pathway performance and has also been used to validate other anaerobic methods (Bertuzzi et al., 2015; Scott et al., 1991; Zagatto et al., 2009). Recent studies investigated the relationship between AC[Epcr + La-] and anaerobic procedures, such as the 30sWAnT and adaptation to running (i.e., 30-s all-out tethered running test) (Bertuzzi et al., 2015; Zagatto et al., 2017). These authors found a significant correlation between AC[Epcr + La-] and peak power (PP) and mean power (MP) for the 30sWAnT ( $\mathrm{r}=0.78$ and 0.79, respectively) and between MP, total work (TW), and mean force (MF) ( $r=0.58 ; 0.57$ and 0.79 , respectively) for the tethered running test, indicating that AC[Epcr + La-] seems to present a relationship with anaerobic indices. However, these studies only compared AC[Epcr + La-] with anaerobic work during the 30sWAnT and a tethered running test, they did not measure the metabolic contribution of the 30sWAnT and the tethered running test, which could strengthen the findings, since the concepts of $\mathrm{AC}$ and anaerobic work are different
(Green, 1995; Minahan et al., 2007).

Therefore, the purpose of the current study was to investigate the relationship between anaerobic energy contribution measured during a supramaximal constant effort (i.e., better intensity for AC[Epcr + La-] measurement) with mechanical and anaerobic contribution during the 30sWAnT. Based on the concept of Bertuzzi et al. (2015) and Zagatto et al. (2017), we hypothesized that AC[Epcr + La-] would be significantly correlated with 30sWAnT mechanical performance (i.e., PP, $\mathrm{MP}$, and TW). In addition, considering the high contribution of anaerobic metabolism to the 30sWAnT (Beneke et al., 2002), the anaerobic contribution during the 30sWAnT may be related with anaerobic energy contribution in a supramaximal continuous effort at $115 \%$ of intensity corresponding to maximal oxygen uptake.

\section{Methods}

\section{Participants}

Fifteen male mountain biking practitioners (Mean \pm SD: age: $30 \pm 4$ yrs; body mass: $76.5 \pm 13.4 \mathrm{~kg}$; body height: $178.6 \pm 7.9 \mathrm{~cm}$; weekly training volume: $237.1 \pm 127.0 \mathrm{~km} \cdot$ week $^{-1}$ ) participated in the current study. Participants were considered recreational cyclists following the Pauwn et al. (2013) guidelines. Before beginning the procedures, participants were informed about the potential risks and benefits of the study, and then signed informed written consent. All procedures were approved by the Local Ethics Committee (Protocol 645.784 / 2014) and were conducted according to the Declaration of Helsinki. In addition, participants were instructed to avoid any substance that could interfere with mechanical performance, such as caffeine and alcohol, and not to perform exhaustive exercises, for at least 24 hours before each session.

\section{Experimental design}

Participants visited the laboratory four times, interspersed with at least $48 \mathrm{~h}$ and all procedures were applied in a maximum period of two weeks. On the first visit, participants performed a familiarization session with a supramaximal effort and a Wingate test. On the second visit, they performed a graded exercise test (GXT) to determine maximal oxygen uptake $\left(\dot{\mathrm{V}}_{2 \max }\right)$ and the intensity associated with $\dot{\mathrm{V}}_{2 \max }$ 
$\left(\mathrm{iVO}_{2 \max }\right)$. On the third and fourth visits, participants randomly performed the supramaximal $115 \%$ of $\mathrm{iVO}_{2 \max }$ test and the 30sWAnT.

All physical fitness tests were performed on an electromagnetic braked cycle ergometer (Lode-Excalibur Sport, Lode BV, Groningen, The Netherlands), in an environment with a controlled temperature and humidity $\left(20 \pm 1^{\circ} \mathrm{C}\right.$ and $63 \pm 10 \%$ respectively). The GXT and the supramaximal test were conducted with a predefined cadence between 70 and $100 \mathrm{rpm}( \pm 5 \mathrm{rpm}$ of a chosen cadence during all efforts). Saddle settings and crank distance from the handlebars were also previously defined, recorded, and used in all efforts. In all tests the warm-up was standardized at $100 \mathrm{~W}$ and five minute duration, however, for the 30sWAnT, two sprints of 2-3 s were performed in the $3^{\text {rd }}$ and $4^{\text {th }}$ min of the warm-up (Beneke et al., 2002).

\section{Physiological analysis}

During all tests, respiratory gas exchange was measured breath-by-breath using a stationary gas analyzer (Quark PFT, COSMED, Rome, Italy), while the heart rate was monitored with a heart rate transmitter belt (Wireless HR 138 Monitor, COSMED, Rome, Italy). The equipment was calibrated immediately before each procedure, according to the manufacturer's recommendations. The respiratory gas exchange values obtained were smoothed every five points and then interpolated every second using OriginPro 8.0 software (OriginLab Corporation, Microcal, Massachusetts, USA) to reduce the "noise".

Blood samples were collected from the ear-lobe $(25 \mu \mathrm{L})$ at rest (before the supramaximal test and the 30sWAnT) to measure baseline blood lactate concentration ([La-baseline]) and at minutes 3, 5 , and 7 after all efforts to measure the peak of blood lactate concentration ([La-peak]). The samples were stored at $-20^{\circ} \mathrm{C}$ in Eppendorf ${ }^{\circledR}$ tubes containing $50 \mu \mathrm{L}$ of $1 \%$ sodium fluoride and subsequently analyzed using an electrochemical lactate analyzer (YSI 2900, Yellow Springs Instruments, Ohio, USA) with a standard error of $\pm 2 \%$.

\section{Graded exercise test (GXT)}

The graded exercise test was designed to lead to exhaustion in $~ 8-12$ min (Howley et al., 1995). Thus, the initial intensity corresponded to
100-125 W, which was increased by $25 \mathrm{~W}$ every 2 min until voluntary exhaustion or the inability to continue the effort at the pre-established cadence (Miyagi et al., 2017).

The oxygen uptake for each completed stage was measured during the final $30 \mathrm{~s}$ of every stage. $\dot{\mathrm{V}}_{2 \max }$ was assessed using the plateau criteria $\left(<2.1 \mathrm{~mL} \cdot \mathrm{kg}^{-1} \cdot \mathrm{min}^{-1}\right.$ between last two stages) (Billat, 2001). If an oxygen uptake plateau was not observed, $\dot{\mathrm{V}} \mathrm{O}_{2 \max }$ was determined considering the verification of at least 2 of the following criteria: maximal heart rate $\geq 90 \%$ of the predicted heart rate (i.e., 220 - age); respiratory exchange ratio (RER) $\geq 1.10$; and peak blood lactate concentration $\geq 8.0 \mathrm{mmol} \cdot \mathrm{L}^{-1}$ (Howley et al., 1995). The GXT was repeated when the criteria were not achieved. The lowest intensity at which $\dot{\mathrm{V}} \mathrm{O}_{2 \max }$ was reached was considered $\mathrm{iVO}_{2 \max }$. If the last stage was not completed, $\mathrm{iVO}_{2 \max }$ was measured using the following equation (equation 1) (Kuipers et al., 1985):

$$
\begin{aligned}
& \text { (Eq.1) } \\
& \mathrm{i} \mathrm{VO}_{2 \max }=\text { Completed power }+\left(\text { Increment } \cdot \frac{\text { Time of the uncompleted stage }}{\text { Time of the full stage }}\right)
\end{aligned}
$$

Completed power and increment power were expressed in watts $(\mathrm{W})$; time of uncompleted stage and time of the full stage were expressed in seconds (s).

Supramaximal exhaustive effort at $115 \%$ of iVO ${ }_{2 \max }$

Before the warm-up participants remained quietly seated for $10 \mathrm{~min}$ for measurement of the baseline oxygen uptake and collection of resting blood lactate. After the warmup, participants performed a supramaximal effort at $115 \%$ of $i \mathrm{VIO}_{2 \max }$, until voluntary exhaustion or the inability to carry out the effort at the preestablished cadence. This intensity has been shown to be the best for determining the $\mathrm{AC}_{[\mathrm{Epcr}+}$ La-] (Miyagi et al., 2017; Zagatto et al., 2016). Immediately after the supramaximal effort, participants remained quietly seated on the bike for $10 \mathrm{~min}$, to measure post-exercise oxygen uptake (Miyagi et al., 2017)

\section{0-s Wingate Anaerobic Test (30sWAnT)}

Before the warm-up and immediately after the test, participants remained quietly seated for $10 \mathrm{~min}$ to measure the same variables reported in the supramaximal effort. The 30-s Wingate Anaerobic Test (30sWAnT) corresponded to an all-out effort of $30 \mathrm{~s}$ with fixed resistance $(0.7$ 
$\left.\mathrm{N} \cdot \mathrm{m} \cdot \mathrm{kg}^{-1}\right), \quad$ following the manufacturer's recommendations (Standard Wingate test Wingate, Lode Manager 10.0, Lode, Netherlands) (Outlaw et al., 2014). Power and pedaling frequency were measured with acquisition data of $50 \mathrm{~Hz}$ throughout the test. The peak power (PP) was considered the highest value of power achieved during the test. The mean power (MP), fatigue index (FI) [(PP - Lower power) $x$ 100)/PP], and total work (TW) were also measured.

\section{Energetic pathways and anaerobic capacity measurements}

The energetic contribution from the phosphagen pathway (EPCr), glycolytic pathway $\left(\mathrm{E}_{[\mathrm{La}-]}\right)$, and anaerobic capacity $\left.\left(\mathrm{AC}_{[\mathrm{Epcr}}+\mathrm{La}-\right]\right)$ were measured in the supramaximal exhaustive effort at $115 \%$ of $\mathrm{iVO}_{2 \max }$ (i.e., $\mathrm{EPCr}_{\mathrm{F}} \mathrm{E}_{[\mathrm{La}-]}$ and $\mathrm{AC}_{[\mathrm{Epcr}+\mathrm{La}] \text { ] }}$. In addition, for the 30sWAnT the phosphagen contribution (30sWAnT-Epcr), glycolytic contribution (30sWAnT-E[La-]) and anaerobic contribution (30sWAnT-AC $[$ Epcr + La-] $)$ were also measured.

The energy delivered from Epcr was estimated as the product between amplitude 1 $\left(\mathrm{A}_{1}\right)$ and time constant $1\left(\tau_{1}\right)$, calculated using a biexponential fit (equation 2) in the post-exercise oxygen uptake slope, using software OriginPro 8.0 (Origin Lab Corporation, Microcal, MA, USA) (Bertuzzi et al., 2010; Miyagi et al., 2017; Zagatto et al., 2016). The energy delivered from E[La-]was estimated by the difference between the peak and rest blood lactate concentration, assuming an oxygen equivalent of $3 \mathrm{~mL} \cdot \mathrm{kg}^{-1}$ for each 1.0 $\mathrm{mmol} \cdot \mathrm{L}^{-1}$ net lactate (Di Prampero and Ferretti, 1999). Finally the $A C_{[E p c r}+$ La- $]$ was assumed as the sum of energetics from $E_{P C r}$ and $E_{[L a-]}$ for the supramaximal exhaustive effort at $115 \%$ of i $\mathrm{VO}_{2 \max }$ and 30sWAnT (Bertuzzi et al., 2010; Miyagi et al., 2017; Zagatto et al., 2016). In addition, the $\mathrm{AC}_{[\mathrm{Epcr}}+$ La-] was also presented relativized by time to exhaustion (in seconds) during the supramaximal effort and during the 30sWAnT.

$$
\text { (Eq 2) } \quad \dot{\mathrm{V}} \mathrm{O}_{2(\mathrm{t})}=\dot{\mathrm{V}} \mathrm{O}_{2 \text { rest }}+\mathrm{A}_{1}\left[\mathrm{e}^{-(-\mathrm{t} \delta) / \tau_{1}}\right]+\mathrm{A}_{2}\left[\mathrm{e}^{-(-\mathrm{t}-\delta) / \tau_{2}}\right]
$$

\section{Statistical analysis}

The data are presented as mean \pm standard deviation (SD) and 95\% confidence intervals (CI95\%). Initially, the data were submitted to the Shapiro-Wilk test to verify normality. In addition the Pearson correlation test was used to verify the associations between $\mathrm{AC}_{\text {[Epcr }}+$ La-], mechanical performance variables from the 30-WAnT, and non-oxidative energetic contributions during the 30-WAnT. Correlations were interpreted according to the value of the correlation coefficient, classified as very weak $(0.0$ to 0.2$)$, weak (0.2 to 0.4$)$, moderate (0.4 to 0.7$)$, strong (0.7 to 0.9 ), and very strong (0.9 to 1.0 ) (Rowntree, 1991). Additionally, comparative analysis between the energetics during the supramaximal test and the 30sWAnT was performed using Bland-Altman plots and the intra-class correlation test (ICC) (model: two-way mixed model; type: single measurement; definition: absolute agreement). To verify possible differences, a paired Student $t$ test was used. In all cases, the significance level was $\leq 5 \%(p \leq 0.05)$.

\section{Results}

The exercise duration during the GXT was $14.12 \pm 3.23 \mathrm{~min}(\mathrm{CI} 95 \%=12.32$ to $15.91 \mathrm{~min})$. Only 3 participants reached the oxygen uptake plateau during the GXT, while all participants reached the secondary criteria to confirm $\dot{\mathrm{VO}}_{2 \max }$ reaching $98.13 \pm 30.31 \%(\mathrm{CI} 95 \%=95.13$ to $101.44 \%$ ) of the predicted HR; RER $=1.21 \pm 0.08$ a.u. $(\mathrm{CI} 95 \%=1.17$ to 1.25 a.u. $)$ and $\left[\mathrm{La}-\mathrm{PEAK}_{\mathrm{PEA}}=9.93\right.$ $\pm 2.25 \mathrm{mmol} \cdot \mathrm{L}^{-1}\left(\mathrm{CI} 95 \%=8.68\right.$ to $\left.11.18 \mathrm{mmol} \cdot \mathrm{L}^{-1}\right)$. Considering these results, $\dot{\mathrm{V}} \mathrm{O}_{2 \max }$ was $53.41 \pm 7.30$ $\mathrm{mL} \cdot \mathrm{kg}^{-1} \cdot \mathrm{min}^{-1}\left(\mathrm{CI} 95 \%=49.37\right.$ to $57.45 \mathrm{~mL} \cdot \mathrm{kg}^{-1} \cdot \mathrm{min}^{-}$ 1) and $\mathrm{iVO}_{2 \max }$ was $304.20 \pm 46.14 \mathrm{~W}(\mathrm{CI} 95 \%=$ 278.65 to $329.74 \mathrm{~W})$. Therefore, the intensity at $115 \%$ of $i \mathrm{~V} O_{2 \max }$ was $349.83 \pm 53.05 \mathrm{~W}(\mathrm{CI} 95 \%=$ 320.45 to $379.21 \mathrm{~W})$.

The time to exhaustion in the $115 \%$ of $\mathrm{iV}_{2 \max }$ supramaximal test was $2.86 \pm 0.51 \mathrm{~min}$ $(\mathrm{CI} 95 \%=2.58$ to $3.14 \mathrm{~min})$. Regarding the energetics estimation during the supramaximal exhaustive effort at the $115 \%$ of $\mathrm{iVO}_{2 \max }$ test, $\mathrm{A}_{1}$ and $\tau_{1}$, calculated in the post-exercise oxygen uptake slope were $1.72 \pm 0.46 \mathrm{~L}(\mathrm{C} 195 \%=1.47$ to $1.98 \mathrm{~L})$ and $0.86 \pm 0.15 \mathrm{~min}(\mathrm{C} 195 \%=0.77$ to 0.94 min), respectively, thus Epcr was $1.44 \pm 0.46 \mathrm{~L}$ $(\mathrm{C} 195 \%=1.16$ to $1.72 \mathrm{~L})$, while [La-baseline] was 1.07 $\pm 0.30 \mathrm{mmol} \cdot \mathrm{L}^{-1}\left(\mathrm{CI} 95 \%=0.90\right.$ to $\left.1.23 \mathrm{mmol} \cdot \mathrm{L}^{-1}\right)$ and [La-peak] was $12.44 \pm 1.65 \mathrm{mmol} \cdot \mathrm{L}^{-1}(\mathrm{CI} 95 \%=$ 11.53 to $\left.13.35 \mathrm{mmol} \cdot \mathrm{L}^{-1}\right)$, thus the $\mathrm{E}_{[\text {La-] }}$ was $2.59 \pm$ $0.86 \mathrm{~L}(\mathrm{CI} 95 \%=2.26$ to 2.93$)$. Considering that, $\mathrm{AC}_{\text {[Epcr }+ \text { La-] }}$ corresponded to $4.02 \pm 0.86 \mathrm{~L}$ (3.50 to $4.54 \mathrm{~L}) . \mathrm{AC}_{[\mathrm{Ep} c r}+$ La-] relativized by time to 
exhaustion during the supramaximal test was $0.024 \pm 0.004 \mathrm{~L}$ per s $(\mathrm{CI} 95 \%=0.022$ to $0.026 \mathrm{~L}$ per s).

Table 1 shows the values of mechanical outcomes from the 30sWAnT, corresponding to $\mathrm{PP}, \mathrm{MP}$, fatigue index (FI), and time to $\mathrm{PP}$ and TW.

Regarding the energetics estimation during the 30sWAnT, $\mathrm{A}_{1}(\mathrm{n}=13)$ was $1.34 \pm 0.25 \mathrm{~L}$ $(\mathrm{CI} 95 \%=1.18$ to $1.49 \mathrm{~L})$ and $\tau_{1}(\mathrm{n}=13)$ was $1.11 \pm$ $0.21 \mathrm{~min}(\mathrm{CI} 95 \%=0.98$ to $1.24 \mathrm{~min})$, thus the 30sWAnT-Epcr $(\mathrm{n}=13)$ was $1.47 \pm 0.36 \mathrm{~L}(\mathrm{CI} 95 \%=$ 1.26 to $1.69 \mathrm{~L})$. For the measurement of the glycolytic pathway, [La-baseline] was $0.99 \pm 0.19$ $\mathrm{mmol} \cdot \mathrm{L}^{-1}\left(\mathrm{C} 195 \%=0.88\right.$ to $\left.1.09 \mathrm{mmol} \cdot \mathrm{L}^{-1}\right)$ and [Lapeak ] was $11.73 \pm 2.20 \mathrm{mmol} \cdot \mathrm{L}^{-1}$, therefore the 30sWAnT-E[La-] was $2.44 \pm 0.69 \mathrm{~L}(\mathrm{CI} 95 \%=2.02$ to $2.85 \mathrm{~L})$. The $30 \mathrm{sWAnT}-\mathrm{AC}$ [Epcr + La-] $(\mathrm{n}=13)$ was 3.91 $\pm 0.89 \mathrm{~L}(\mathrm{C} 195 \%=3.38$ to $4.45 \mathrm{~L})$, while the 30 WAnT-AC $\mathrm{C}_{\text {[Epcr }+ \text { La-] }}$ relativized by the $30 \mathrm{sWAnT}$ was $0.130 \pm 0.030 \mathrm{~L}$ per s $(\mathrm{CI} 95 \%=0.113$ to $0.148 \mathrm{~L}$ per s). During the 30sWAnT, two participants felt nausea caused by acidosis, preventing the postexercise oxygen uptake measurement, for this reason, only 13 participants were analyzed for 30sWAnT-Epcr and for 30sWAnT-AC [Epcr + La-].
No difference was observed between nonoxidative energetic contribution measured during the $115 \%$ of $\mathrm{iVO}_{2 \max }$ supramaximal exhaustive test and the 30sWAnT (Figure 1). In addition, the intra-class correlation showed good reliability between Epcr $\mathrm{x}$ 30sWAnT-Epcr (ICC $=0.70 ; p=$ $0.004), \mathrm{E}_{\text {[La-] }} \times 30$ sWAnT-E[La-] $($ ICC $=0.87 ; p=$ 0.001), and $\mathrm{AC}_{\text {[Epcr }+ \text { La-] }} \mathrm{x}$ 30sWAnT-AC $\mathrm{C}_{\text {[Epcr }+ \text { La-] }}$ $(\mathrm{ICC}=0.84 ; p=0.001)$. Furthermore, good agreement was observed, evidenced by the mean of differences and $95 \%$ limits of agreement close to zero (Figure 2).

In addition, the coefficients of correlation between energetics measured during the $115 \%$ of $\mathrm{iV}_{2 \max }$ supramaximal test and mechanical performance in the 30sWAnT are presented in Table 2. A moderate significant correlation was observed between the supramaximal test $\mathrm{EPCr}_{\mathrm{r}}$ and $\mathrm{PP}, \mathrm{MP}$, and TW. In addition, a strong coefficient of correlation was observed between $\mathrm{E}_{[\mathrm{La}-\mathrm{j}}$ and $\mathrm{AC}_{\text {[Epcr }+ \text { La- }]}$ and PP, MP, and TW. Finally, no significant correlations were observed between any energetic contributions of the supramaximal test and FI.

Table 1

The 30sWAnT mechanical variables.

\begin{tabular}{lc}
\hline Variables & \\
\hline Peak Power (W) & $688.15 \pm 133.00(607.78$ to 768.53$)$ \\
Mean Power (W) & $60.96 \pm 6.15$ (57.24 to 64.68$)$ \\
Rate of Fatigue (\%) & $2.47 \pm 0.84(2.00$ to 2.93$)$ \\
Time to Peak Power (s) & $20.49 \pm 3.95$ (18.10 to 22.88) \\
Total Work (kJ) & \\
\hline
\end{tabular}

Values are mean \pm SD (C195\%) 
Table 2

Coefficient of correlation between energetics measured during the supramaximal effort at $115 \%$ of $i \mathrm{VO}_{2 \max }$ and mechanical performance in the $30 \mathrm{sWAnT}$. Peak Power Mean Power Total Work Fatigue index (\%)

(W)

(W)

$(\mathrm{kJ})$

\begin{tabular}{|c|}
\hline $\operatorname{EpCr}(\mathrm{L}$ \\
\hline
\end{tabular}

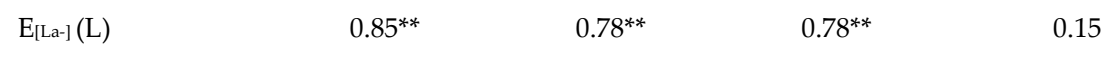

$\begin{array}{lllll}\mathrm{AC}_{[\mathrm{Epcr}+\mathrm{La}-]}(\mathrm{L}) & 0.88^{* *} & 0.89^{* *} & 0.89^{* *} & 0.19\end{array}$

${ }^{*}$ significant correlation at $p \leq 0.05$ level ; ${ }^{* *}$ significant correlation at $p \leq 0.01$ level.

$E_{P C r}=$ phosphagen pathway; $E_{[L a-]}=$ glycolytic pathway; $A C_{[E p c r+L a-]}=$ anaerobic capacity .
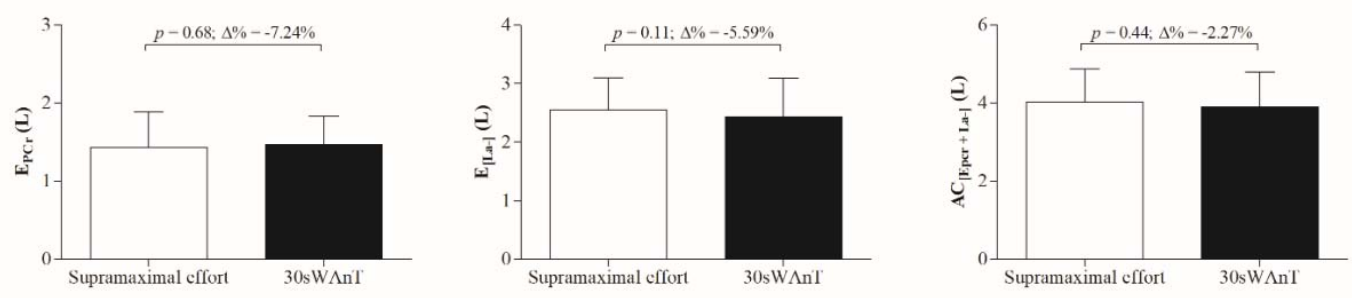

Figure 1

Comparison and percentage of variation $(\Delta \%)$ in non-oxidative energetics measured during the $115 \%$ of $i \dot{V} O_{2 m a x}$ supramaximal test and the $30 \mathrm{sWAnT}$. 

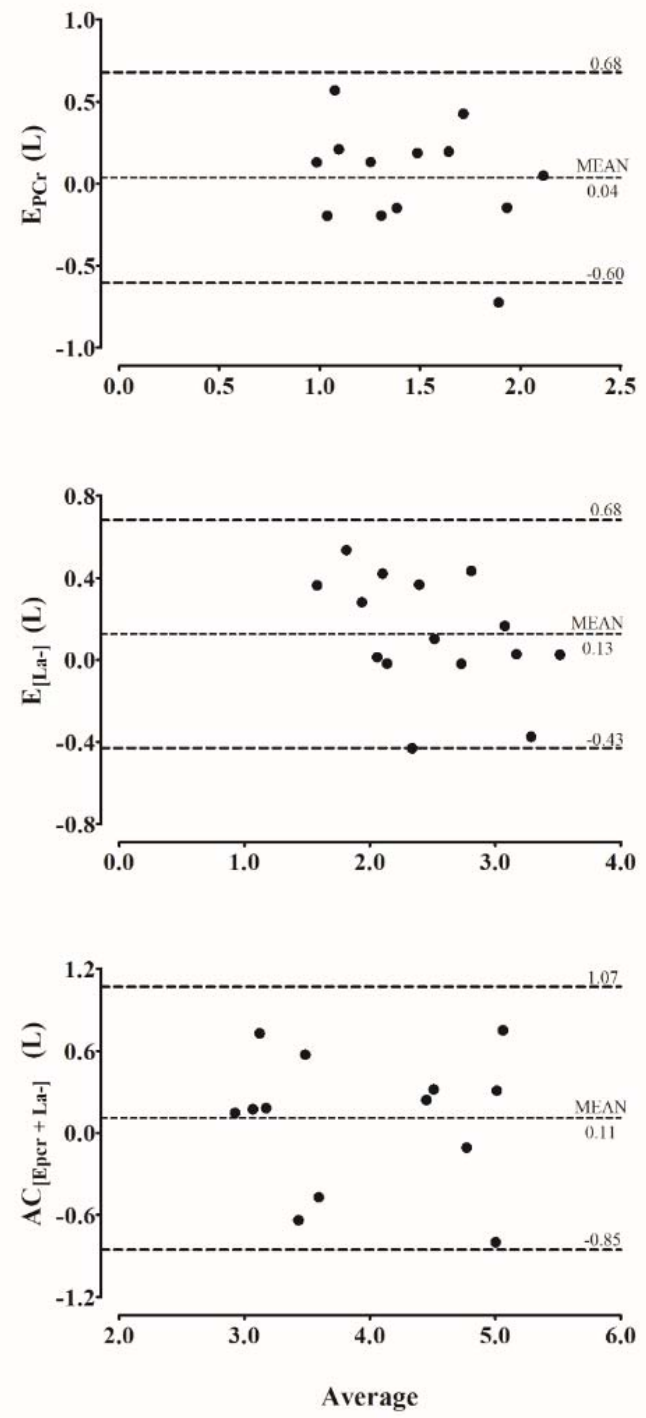

Figure 2

Bland-Altman plot for comparison of mean difference between non-oxidative energetics measured during the $115 \%$ of $i \dot{V} O_{2 \max }$ supramaximal test and the $30 \mathrm{sWAnT}$.

\section{Discussion}

The main findings of the study reveal a good relationship between non-oxidative pathways measured during supramaximal exhaustive effort at $115 \%$ of $\quad \mathrm{iV}_{2 \max }$
$($ EPCr, E[La- $]$, and AC[Epcr + La- $])$ and mechanical performance during the 30sWAnT (PP, MP, and TW). In addition, EPCr, E[La-], and $\mathrm{AC}[\mathrm{Epcr}+\mathrm{La}-]$ measured during the $115 \%$ of $\mathrm{iVO}_{2 \max }$ supramaximal test (best intensity to estimate anaerobic capacity) demonstrated good 
agreement and a significant relationship with the contribution of this pathway during the 30sWAnT.

The significant correlations between the phosphagen pathway and PP are in accordance with a previous investigation which also reported a significant correlation between these metabolic and mechanical variables in cycling $(r=0.71)$ (Bertuzzi et al., 2015). The possible explanation for this association between EPCr and PP may be related to the energetic aspect of the 30sWAnT, as this effort can deplete phosphocreatine stores by $\sim 83 \%$ (Bogdanis et al., 1996), mainly during the initial three seconds of effort (Serresse et al., 1988), which also corroborates the time to PP observed in the present investigation $(2.47 \pm 0.84 \mathrm{~s})$. In addition, EPCr was also correlated with MP and TW, suggesting that EPCr, besides playing an important role during the first seconds of the effort, also plays a significant role during all efforts lasting around $30 \mathrm{~s}$. These findings corroborate the findings from Milioni et al. (2017), which reported a significant correlation between mean power during a repeated $35-\mathrm{m}$ sprint test (i.e., 30sWAnT adaptation to track running) and the phosphagen pathway $(r=0.65)$. In addition, energy contribution of the phosphagen pathway during the 30sWAnT is relevant ( 31\%) (Beneke et al., 2002), a fact that may strengthen the importance of this metabolic pathway for power output during the 30sWAnT.

As well as EPCr, the glycolic pathway measured during the supramaximal test was also significantly associated with PP, MP, and TW. The blood lactate concentration is related to nonoxidative work and mechanical performance (Fujitsuka et al., 1982), eventually exerting a direct influence on E[La-] (i.e., main indicator of E[La]contribution). Bertuzzi et al. (2015) also reported a positive relationship between E[La-] and MP $(r=$ 0.72); the authors did not report any correlation data between this energetic pathway and other mechanical performance variables during the 30sWAnT. The glycolytic pathway can provide around $50 \%$ of total energy (i.e., non-oxidative plus oxidative phosphorylation contributions) of the 30 sWAnT, explaining $83 \%$ and $81 \%$ of the variance in PP and MP, respectively (Beneke et al., 2002). Furthermore, the 30sWAnT can deplete glycogen content by $\sim 30 \%$, which accounts for $97 \%$ by glycolytic intermediates (i.e., pyruvate and lactate) (Bogdanis et al., 1996). Together, this evidence probably explains the relationship between $\mathrm{E}[\mathrm{La}-]$ and mechanical performance during the 30sWAnT.

Considering the importance of glycolytic and phosphagen contribution to the 30sWAnT energetics (i.e., $81.4 \%$ of total energy contribution) (Beneke et al., 2002) and, consequently, to mechanical performance (Bertuzzi et al., 2015; Bogdanis et al., 1996; Milioni et al., 2017), our results (i.e., significant correlation between $\mathrm{AC}[\mathrm{Epcr}+\mathrm{La}-]$ and PP, MP, and TW) are expected, since anaerobic capacity is the sum of phosphagen and glycolytic contributions. These results are also in accordance with the findings of Scott et al. (1991), as those authors reported a significant correlation between anaerobic capacity measured by maximal accumulated oxygen deficit with both PP and TW ( $\mathrm{r}=0.69$ and 0.64, respectively) for a group of heterogeneous runners $(n=12)$. Another study has demonstrated a non-significant correlation between anaerobic capacity measured by maximal accumulated oxygen deficit and mechanical variables from the 30sWAnT (Minahan et al., 2007).

These contradictory results may be attributed to the evaluation method, since in those studies different numbers of submaximal efforts were used, and the intensity of the supramaximal effort was different. In fact, these differences can influence the reliability of the maximal accumulated oxygen deficit method (Doherty et al., 2000). On the other hand, the method used to estimate anaerobic capacity in the present study (i.e., $\mathrm{AC}[\mathrm{Epcr}+\mathrm{La}-])$ presents higher reliability than the maximal accumulated oxygen deficit method (de Poli et al., 2019), and thus may be more robust to estimate anaerobic capacity. It is noteworthy that, besides mechanical performance during the 30sWAnT being more dependent and associated with mechanical power output, even when compared with oxidative mechanical variables (e.g. $\mathrm{iV}_{2 \max }$ and respiratory compensation point) (Malta et al., 2018), our findings showed significant associations between the 30sWAnT and anaerobic energy contribution measured on an electro-magnetically braked cycle ergometer, reinforcing the importance of anaerobic metabolism for 30sWAnT mechanical performance (Bertuzzi et al., 2015).

Another interesting finding in the current 
study is the possibility of estimating phosphagen and glycolytic pathway capacity, and consequently anaerobic capacity during the 30sWAnT. In general, anaerobic capacity (i.e., maximum ATP resynthesized by a non-oxidative source during a specific effort) is estimated during supramaximal efforts that lead to exhaustion between the 2nd and the 3rd minute (Medbø et al., 1988; Miyagi et al., 2017; Zagatto et al., 2016, 2018), regardless of the anaerobic training status (Zagatto et al., 2017), considering that this time to exhaustion is required for severe depletion of phosphocreatine and glycogen stores (Medbø and Tabata, 1993). Besides this, anaerobic capacity measured during the 30sWAnT was not different to that measured in the supramaximal constant effort $(\mathrm{p}=0.44)$ and their absolute values are in line with those previously reported in cycling (Miyagi et al., 2017; Zagatto et al., 2018). In addition, the Bland-Altman concordance analysis (Figure 2) showed a mean difference close to zero between AC[Epcr + La-] measured in the 30sWAnT and supramaximal constant effort, with lower limits of agreement even when compared with previously reported results for a 2-3 $\mathrm{min}$ exhaustive effort (i.e., 3 minutes all-out) $(-1.33$ to 1.13) (Zagatto et al., 2018).

Despite these results, it is important to note that although AC[Epcr + La-] is considered a valid and reliable method for anaerobic capacity estimation and is commonly used for this purpose (Bertuzzi et al., 2010, 2015; Milioni et al., 2017; Miyagi et al., 2017; Zagatto et al., 2016), there are some limitations in the use of blood lactate to estimate the glycolytic metabolism pathway. Despite the fact that blood lactate mirrored muscle lactate concentration, part of lactate is oxidized in the muscle (Bangsbo et al., 1990), underestimating the glycolytic contribution. In addition, the oxygen equivalent blood lactate accumulation proposed by Di Prampero and Ferretti (1999) may not represent the exact stoichiometric ratio between lactate and the ATP resynthesized.

Even considering that the 30sWAnT is not an ideal effort for high depletion of phosphocreatine and mainly glycogen stores (Medbø and Tabata, 1993), similar results between anaerobic capacity measured during the supramaximal exhaustive effort at $115 \%$ of ("iV" ) "O" _"2max" and the 30sWAnT can hypothetically be attributed to greater muscle activation during higher intensity efforts, with a consequently higher rate of glycolytic pathway activation (evidenced by higher concentration of blood lactate) (Thomas et al., 2016) and to severe depletion of phosphocreatine stores (Bogdanis et al., 1996). However, muscle activation and content of muscle glycogen and phosphocreatine were not measured in the present study, thus further studies are needed to test this hypothesis. In addition, the possibility of estimating anaerobic capacity during the 30sWAnT must be assumed only for recreational mountain bike trained individuals (i.e., endurance trial), as sprinters may have a higher rate of non-oxidative energy release (Schenau et al., 1992) and, consequently, different energy release during the 30sWAnT.

In summary, glycolytic and phosphagen capacity, as well as anaerobic capacity determined during a $115 \%$ of $\mathrm{iVO}_{2 \max }$ supramaximal effort were correlated with mechanical performance in the 30sWAnT (i.e., PP, MP, and TW), and were also associated with anaerobic pathways measured during the 30sWAnT.

\section{Acknowledgements}

The authors declare there was no conflict of interest in the completion of this study. RABP and WEM were supported by the São Paulo Research Foundation (FAPESP) fellowship (\#2019/17445-1 and 2014/028295, respectively). This study was financed by the São Paulo Research Foundation (FAPESP) (\#2013/12940-8) and in part by the Coordenação de Aperfeiçoamento de Pessoal de Nível Superior - Brasil (CAPES) - Finance Code 001 .

\section{References}

Bangsbo J, Gollnick PD, Graham TE, Juel C, Kiens B, Mizuno M, Saltin B. Anaerobic energy production and O2 deficit-debt relationship during exhaustive exercise in humans. J Physiol, 1990; 422: 539-559

Beneke R, Pollmann C, Bleif I, Leithäuser RM, Hütler H. How anaerobic is the wingate anaerobic test for humans?. Eur J Appl Physiol, 2002; 87(4-5): 388-392 
Bertuzzi RCM, Franchini E, Ugrinowitsch C, Kokubun E, Lima-Silva AE, Pires FO, Nakamura FY,Kiss MAPDM. Predicting MAOD using only a supramaximal exhaustive test. Int J Sports Med, 2010; 31(7): 477-481

Bertuzzi R, Kiss MAPDM, Damasceno M, Oliveira RSF, Lima-Silva AE. Association between anaerobic components of the maximal accumulated oxygen deficit and 30-second Wingate test. Brazilian J Med Biol Res, 2015; 48(3): 261-266

Billat L. Interval Training for Performance: A Scientific and Empirical Practice: Special Recommendations for Middle- and Long-Distance Running. Part I: Aerobic Interval Training. Sport Med, 2001; 31(1): 13-31

Bogdanis GC, Nevill ME, Boobis LH, Lakomy HK. Contribution of phosphocreatine and aerobic metabolism to energy supply during repeated sprint exercise. J Appl Physiol, 1996; 80(3): 876-884

de Poli RAB, Roncada LH, Malta E de S, Artioli GG, Bertuzzi R, Zagatto AM. Creatine supplementation improves phosphagen energy pathway during supramaximal effort, but does not improve anaerobic capacity or performance. Front Physiol, 2019; 10: 352

Di Prampero PE, Ferretti G. The energetics of anaerobic muscle metabolism: A reappraisal of older and recent concepts. Respir Physiol, 1999; 118(2-3): 103-115

Doherty M, Smith PM, Schroder K. Reproducibility of the maximum accumulated oxygen deficit and run time to exhaustion during short-distance running. J Sports Sci, 2000; 18(5): 331-338

Foster C, Dekoning JJ, Hettinga F, Lampen J, Dodge C, Bobbert M, Porcari JP. Effect of competitive distance on energy expenditure during simulated competition. Int J Sports Med, 2004; 25(3): 198-204

Foster C, De Koning JJ, Hettinga F, Lampen J, La Clair KL, Dodge C, Bobbert M, Porcari JP. Pattern of energy expenditure during simulated competition. Med Sci Sports Exerc, 2003; 35(5): 826-831

Fujitsuka N, Yamamoto T, Ohkuwa T, Saito M, Miyamura M. Peak blood lactate after short periods of maximal treadmill running. Eur J Appl Physiol Occup Physiol, 1982; 48(3): 289-296

Green S. Measurement of Anaerobic Work Capacities in Humans. Sport Med, 1995; 19(1): 32-42

Howley ET, Bassett DR, Welch HG. Criteria for maximal oxygen uptake: review and commentary. Med Sci Sports Exerc, 1995; 27(9): 1292-1301

Kuipers H, Verstappen FTJ, Keizer HA, Geurten P, van Kranenburg G. Variability of aerobic performance in the laboratory and its physiologic correlates. Int J Sports Med, 1985; 6(4): 197-201

Malta ES, Brisola GMP, de Poli RAB, Dutra YM, Franchini E, Zagatto AM. Metabolic Profile and Performance Responses During Two Consecutive Sessions of Sprint Interval Training. J Strength Cond Res, 2020; 34(4): 1078-1085

Margaria R, Edwards H, Dill D. The possible mechanisms of contracting and paying the oxygen debt and the role of lactic acid in muscular contraction. Am J Physiol, 1933; 106(3): 689-715

Medbø JI, Mohn AC, Tabata I, Bahr R, Vaage O, Sejersted OM. Anaerobic capacity determined by maximal accumulated O2 deficit. J Appl Physiol, 1988; 64(1): 50-60

Medbø JI, Tabata I. Anaerobic energy release in working muscle during $30 \mathrm{~s}$ to $3 \mathrm{~min}$ of exhausting bicycling. J Appl Physiol, 1993; 75(4): 1654-1660

Milioni F, Zagatto AM, Barbieri RA, Andrade VL, Dos Santos JW, Gobatto CA, da Silva ASR, Santiago PRP, Papoti M. Energy systems contribution in the running-based anaerobic sprint test. Int J Sports Med, 2017; 38(3): 226-232

Minahan C, Chia M, Inbar O. Does power indicate capacity? 30-S wingate anaerobic test vs. maximal accumulated $\mathrm{O} 2$ deficit. Int J Sports Med, 2007; 28(10): 836-843

Miyagi WE, de Poli RAB, Papoti M, Bertuzzi R, Zagatto AM. Anaerobic Capacity estimated in A Single Supramaximal Test in Cycling: Validity and Reliability Analysis. Sci Rep, 2017; 7:42485

Outlaw JJ, Wilborn CD, Smith-Ryan AE, Hayward SE, Urbina SL, Taylor LW, Foster CA. Effects of a pre-and post-workout protein-carbohydrate supplement in trained crossfit individuals. Springerplus, 2014; 3(1): $1-7$

Pauw K De, Roelands B, Geus B De, Meeusen R. Guidelines to classify subject groups in sport- science research. Int J Sports Physiol Perform, 2013; 8(2): 111-122

Rowntree D. Statistics without tears : a primer for non-mathematicians. London: Penguin Books; 1991 
Scott CB, Roby FB, Lohman TG, Bunt JC. The maximally accumulated oxygen deficit as an indicator of anaerobic capacity. Med Sci Sports Exerc, 1991; 23(5): 618-624

Serresse O, Lortie G, Bouchard C, Boulay MR. Estimation of the contribution of the various energy systems during maximal work of short duration. Int J Sports Med, 1988; 9(6): 456-460

Spencer MR, Gastin PB. Energy system contribution during 200-to 1500-m running in highly trained athletes. Med Sci Sports Exerc, 2001; 33(1): 157-162

Thomas K, Elmeua M, Howatson G, Goodall S. Intensity-Dependent Contribution of Neuromuscular Fatigue after Constant-Load Cycling. Med Sci Sports Exerc, 2016; 48(9): 1751-1760

Van Ingen Schenau GJ, De Koning JJ, De Groot G. The distribution of anaerobic energy in 1000 and 4000 metre cycling bouts. Int J Sports Med, 1992; 13(6): 447-451

Zagatto AM, Beck WR, Gobatto CA. Validity of the running anaerobic sprint test for assessing anaerobic power and predicting short-distance performances. J Strength Cond Res, 2009; 23(6): 1820-1827

Zagatto AM, Bertuzzi R, Miyagi WE, Padulo J, Papoti M. MAOD Determined in a Single Supramaximal Test: A Study on the Reliability and Effects of Supramaximal Intensities. Int J Sports Med, 2016; 37(9): 700-707

Zagatto AM, Nakamura FY, Milioni F, Miyagi WE, de Poli RAB, Padulo J, Bragazzi NL, Papoti M. The sensitivity of the alternative maximal accumulated oxygen deficit method to discriminate training status. J Sports Sci, 2017; 35(24): 2453-2460

Zagatto AM, Miyagi WE, De Barros Sousa FA, Gobatto CA. Relationship between anaerobic capacity estimated using a single effort and 30-s tethered running outcomes. PLoS One, 2017; 12(2): e 0172032

Zagatto AM, Redkva PE, de Poli RAB, González JAM, Brandani JZ, Penedo T, Bertuzzi RCM. 3-min all-out effort on cycle ergometer is valid to estimate the anaerobic capacity by measurement of blood lactate and excess post-exercise oxygen consumption. Eur J Sport Sci, 2018; 19(5): 645-652

\section{Corresponding author:}

\section{Alessandro Moura Zagatto, PhD.}

Laboratory of Physiology and Sport Performance (LAFIDE); Department of Physical Education, School of Sciences, São Paulo State University (UNESP), Av. Eng. Luiz Edmundo Carrijo Coube, 14-01, Vargem Limpa, CEP 17033-360, Bauru, SP, Brazil.

Phone/Fax: +55 1431036082 Branch Line: 9620

E-mail: azagatto@yahoo.com.br 